\title{
Evaluation of the Anti-inflammatory and Sedative Effects of Leaf Aqueous Extract of Withania somnifera (L.) Dunal (Solanaceae) in Rats and Mice
}

\author{
George Jimboyeka Amabeoku, Oluchi Nneka Mbamalu, Munira Ismail, Nabeel Dudhia, Nadeem Noordien, \\ Zukiswa Mabuya and Oatlhostse Kakutsi \\ Discipline of Pharmacology, School of Pharmacy, University of the Western Cape, Private Bag X17, Bellville 7535, South Africa
}

\begin{abstract}
The use of medicinal plants in South Africa is cultural. Withania somnifera is one of the medicinal plants used to treat various ailments in the country. The plant species has been used by traditional medicine practitioners to treat inflammation and painful conditions like rheumatism. It is also known to be used as a sedative and hypnotic drug. Despite the claims, there is no information in literature to corroborate the therapeutic success of Withania somnifera in the treatment of inflammation and insomnia. The study, therefore, investigated the anti-inflammatory and central nervous system depressant activities of the leaf aqueous extract of the plant species in mice and rats. Fresh leaves of $W$. somnifera were collected from Kirstenbosch Botanical Gardens, South Africa, authenticated by a taxonomist and a voucher specimen (UWC 005) deposited in the University's Herbarium. Leaf aqueous extract was prepared using standard extraction methods. The carrageenan-induced rat paw oedema test was used to determine the anti-inflammatory effects while pentobarbitone-induced sleep and locomotor activity tests were used to evaluate the sedative effect of the plant species. Phytochemical qualitative analysis, acute toxicity and HPLC studies of the plant species were also carried out using standard methods. The phytochemical qualitative analysis carried out on the dried powdered leaves of W. somnifera showed the presence of saponins, tannins and triterpene steroids. Leaf aqueous extract of $W$. somnifera $(100-200 \mathrm{mg} / \mathrm{kg}$ IP) significantly prolonged pentobarbitone (40 mg/kg, i.p.)-induced sleep in mice in a dose dependant manner. Diazepam $(0.5 \mathrm{mg} / \mathrm{kg}$, i.p. $)$ significantly prolonged pentobarbitone ( $40 \mathrm{mg} / \mathrm{kg}$, i.p.)-induced sleep in mice. The doses of 100 and $200 \mathrm{mg} / \mathrm{kg}$ (i.p.) of the plant species and $0.5 \mathrm{mg} / \mathrm{kg}$ (i.p.) of diazepam significantly reduced the locomotor activity of mice. Leaf aqueous extract of the plant species $(50-200 \mathrm{mg} / \mathrm{kg}$, i.p.) significantly reduced the oedema produced by carrageenan (1\%) in rats over $90 \mathrm{~min}$ period of testing. Indomethacin (20 mg/kg, i.p.) significantly reduced carrageenan (1\%)-induced oedema in rats over $120 \mathrm{~min}$ period of testing. The $\mathrm{LD}_{50}$ value obtained for the leaf aqueous extract of the plant species following inter-peritoneal injection was $1,600 \mathrm{mg} / \mathrm{kg}$ while that following oral administration was probably over $4,000 \mathrm{mg} / \mathrm{kg}$. The HPLC finger-print of the aqueous extract showed distinct peaks at the following retention times 2.977 , $3.594,4.154,4.406,4.660$ and $15.267 \mathrm{~min}$. The results obtained show that leaf aqueous extract of $W$. somnifera has both sedative and anti-inflammatory effects.
\end{abstract}

Key words: Withania somnifera, solanaceae, leaf aqueous extract, anti-inflammatory activity, Pentobarbitone-induced sleep test, locomotor activity, phytochemical analysis, acute toxicity, HPLC study, mice, rats.

\section{Introduction}

Medicinal plants are part of the cultural heritage of South Africa. There are about 3,000 species of plants used as medicines in South Africa. Withania somnifera (L.) Dunal is one of the medicinal plants used to treat

Corresponding author: George Jimboyeka Amabeoku, Ph.D., professor, research fields: pharmacology and ethnopharmacology. E-mail: gamabeoku@uwc.ac.za. various ailments in the country. The plant species belongs to the family of Solanaceae. It is a short shrub with a central stem from which branches extend radially in a star pattern. The leaves are velvety, oblong and pale green and covered with short, fine, silver grey dense hairs. The flowers are small and white or yellow in colour, while the ripe fruit or berry is orange-red [1]. It is widespread and found in most of the provinces in South Africa and also in other parts of Africa, southern 
Europe and Asia [2, 3]. W. somnifera is locally known as "ubuvimbha" in Zulu, "ubuvuma" in Xhosa, "bofepha" in Sotho and "geneesblaarbossie" in Afrikaans. It is also known in English as Winter cherry [1]. Infusion of the leaves has been used to treat abscesses, inflammation, haemorrhoids, rheumatism and syphilis. The plant species has been used as a sedative and hypnotic to treat people experiencing intermittent periods of stress, a general and inherent tendency towards anxiety and nervousness and bouts of insomnia $[1,2,4,5]$. Even though traditional medicine practitioners have made claims of effectiveness of the plant species in the treatment and/or management of inflammatory conditions and insomnia, no evidence of any scientific scrutiny has been found in any literature to verify the claims. The study therefore, intended to evaluate the anti-inflammatory and sedative effects of leaf aqueous extract of Withania somnifera in rats and mice. The aim of the study also included the phytochemical quanlitative and HPLC analyses, and acute toxicity study of the plant species.

\section{Materials and Methods}

\subsection{Plant Material}

Fresh leaves of Withania somnifera were collected from Kirstenbosch Botanical Gardens, Republic of South Africa and authenticated by the curator of Kirstenbosch Botanical Gardens and a taxonomist in the Department of Biodiversity and Conservation Biology, University of the Western Cape. A voucher specimen of the plant (Amabeoku 005(UWC)) was then deposited in the University's Herbarium.

\subsection{Preparation of the Aqueous Extract of Withania somnifera}

The fresh leaves were stripped from the branches and weighed $(660 \mathrm{~g})$. They were dried in a ventilated oven at $35^{\circ} \mathrm{C}$ for 5 days. The dried leaves were grounded using a hammer mill and the fine powder obtained was weighed (108 g). Weighed quantity (60g) of the powder was put in to a 1 litre beaker, and 1 litre of boiling water was then added and allowed to cool. Once cooled, the mixture was filtered using a suction filter. The filtrate collected was frozen at $-80^{\circ} \mathrm{C}$ and freeze dried (FREEZONE, Labconco Co., KansasCity, Missouri, USA). A yield of $15.35 \mathrm{~g}$ of dried extract was obtained and stored properly for further use. Fresh plant extract solution was prepared each day of the experiment by dissolving weighed quantity in an appropriate volume of physiological saline. The solutions were administered to the animals intraperitoneally (i.p.) in a volume of $1 \mathrm{ml} / 100 \mathrm{~g}$ of body weight of animal.

\subsection{Animals}

Male and female albino mice weighing 18-30 $\mathrm{g}$ and male Wistar rats weighing 160-260 g, both bred in the Animal house of the Discipline of Pharmacology, UWC were used. The mice and rats were housed in perspex mouse and rat cages respectively. They had free access to food and water ad libitum. The animals were fasted for 16 hours (h) before the experiment, with free access to water. Laboratory conditions of temperature $\left(25 \pm 1{ }^{\circ} \mathrm{C}\right)$, humidity and alternate $12 \mathrm{~h}$ light and $12 \mathrm{~h}$ dark cycle were maintained at all times during the experiments. Each mouse or rat was used for one experiment only.

\subsection{Drugs and Chemicals}

Carrageenan (Sigma Chemical Co.) and pentobarbitone (Kyron Lab Ltd, RSA) were dissolved in physiological saline to appropriate volumes. Indomethacin (Sigma Chemical Co.) was dissolved in minimum amounts of dimethylsulfoxide and made up to an appropriate volume with physiological saline. Diazepam (Valium ${ }^{\circledR}$, Roche, South Africa) was suspended in a minimum volume of polyethylene glycol 400 (Fluka AG, Buchs) and adjusted to an appropriate volume with physiological saline. All the drugs were injected into the animals intraperitoneally (i.p.) in a volume of $1 \mathrm{ml} / 100 \mathrm{~g}$ of body weight of animals. Constant volume of carrageenan (1\%) was 
injected into the sub-plantar surface of the right hind paws of rats. Control animals received equal volume injections of physiological saline. The doses and pre-treatment times of the leaf aqueous extract of $W$. somnifera and the standard drugs used were obtained from preliminary studies in our laboratory. The pre-treatment times, following the administration of carrageenan or pentobarbitone, were $15 \mathrm{~min}$ (plant extract), $30 \mathrm{~min}$ (indomethacin), $15 \mathrm{~min}$ (diazepam) and $15 \mathrm{~min}$ (physiological saline).

\subsection{Phytochemical Analysis}

Phytochemical qualitative analysis was performed on the dried powdered leaf of Withania somnifera using the methods of Harborne [6] and Ikhiri et al. [7] to determine some of the chemical compounds present in the plant species.

\subsection{Pharmacological Activity Assessments, Sedative Effect}

\subsubsection{Pentobarbitone-Induced Sleep Test}

The method of Kitano et al. [8] and Williamson et al. [9] were used to assess the effect of $W$. somnifera on pentobarbitone-induced sleep. Male and female mice were used in groups of eight per dose of plant extract, standard drug or physiological saline. Pentobarbitone, a barbiturate [10] was used to induce sleep in the control mice pre-treated with physiological saline $(0.25$ $\mathrm{ml}$, i.p.) for $15 \mathrm{~min}$. The onset and duration of sleep were noted by means of a stop clock. Mice are said to be asleep when they lose their righting reflex. The time between the loss and recovery of righting reflex was noted as duration of sleep [11, 12]. Experiments were repeated with animals pre-treated for 15 min with either the plant extract or standard sedative-hypnotic drug, diazepam [10], before the administration of pentobarbitone. The interval between loss and recovery of righting reflex has been used as the index of hypnotic effect [13].

2.5.2 Locomotor Activity Test

Modified method of Marazioti et al. [14] was used to assess the effect of $W$. somnifera on the locomotor activity of both male and female mice. Spontaneous motor activity was measured using Ugo Basile Activity Cage, Model 7420 comprising of I.R. Beam Array Perspex animal cage and an electronic unit incorporating a counter and a printer. The perspex animal cage $(41 \mathrm{~cm} \times 41 \mathrm{~cm} \times 33 \mathrm{~cm})$ has horizontal and vertical sensors on its floor for measuring horizontal and vertical activities of animals respectively. The total photocell interruptions by animals at a given time are picked up by the counter and the results are shown by the printer. Eight mice were used per dose of physiological saline, plant extract or standard drug. Mice were placed individually in the cage for $20 \mathrm{~min}$ to acclimatize them to their new environment. The animal was then taken out, pretreated for $15 \mathrm{~min}$ with either physiological saline (i.p.), plant extract (i.p.) or standard drug (i.p.) and returned to the cage where the activity was immediately counted for $15 \mathrm{~min}$. The ability of plant extract to significantly decrease the number of spontaneous locomotor activity in mice was taken as an indication of a sedative effect [15].

\subsection{Anti-inflammatory Activity}

\subsubsection{Rat Paw Oedema Test}

Modified method of Williamson et al. [9] was used to assess the anti-inflammatory activity of $W$. somnifera. Rats were used in groups of 6 per dose of plant extract, standard drug or physiological saline. The animals were kept individually in transparent perspex rat cages before the commencement of the experiment. Control animals were pre-treated for 15 min with $0.25 \mathrm{ml}$ (i.p.) of physiological saline. Acute inflammation or oedema was induced by injecting 0.1 $\mathrm{ml}$ of $1 \%$ carrageenan into the subplantar surface of the right hind paw of the rat. Inflammation or oedema following carrageenan injection was noticeable within $30 \mathrm{~min}$. The volume of the right hind paw was measured before and then after the injection of carrageenan at $30 \mathrm{~min}$ intervals for $4 \mathrm{~h}$ by volume 
displacement method using plethysmometer (TIIC, USA). The experiment was repeated using other groups of animals which were pre-treated with graded doses of plant extract or standard drug. The volumes of the untreated rats' right hind paws were also measured at $30 \mathrm{~min}$ intervals for $4 \mathrm{~h}$. Acute inflammation or oedema was expressed as a mean increase in paw volume with respect to physiological saline control. All the experiments were performed in the pharmacology laboratory between $09 \mathrm{~h} 00$ and $17 \mathrm{~h} 00$. The ability of the plant extract to attenuate the paw oedema was taken as an indication of an anti-inflammatory activity. Inhibition was expressed as a percentage increase or decrease in oedema volume [9].

\subsection{Acute Toxicity}

The method of Lorke [16] was modified and used for the acute toxicity study. Male and female albino mice were used in groups of four per dose of the plant extract. Animals were fasted for $16 \mathrm{~h}$ prior to commencement of the administration of the plant extract. They only had access to water during the fasting period. Graded doses, $100,200,400,800,1,200,1,600,2,000,2,400,2,800$, $3,200,3,600$ and $4,000 \mathrm{mg} / \mathrm{kg}$, of leaf aqueous extract of $W$. somnifera were given to mice orally by means of a bulbed steel needle and another set of animals received the same graded doses intraperitoneally. Another group of four mice was used as the control, being given $0.25 \mathrm{ml}$ of distilled water orally. Animals were observed for five days for any acute toxicity symptoms such as salivation, piloerection, immobility and/or respiratory distress including deaths. Both tests and control mice had access to food and water during the 5 days observation period. If death was recorded within the period of observation, log dose-response curves would be constructed for the plant extract from which the median lethal dose, $\mathrm{LD}_{50}$, would be calculated.

\subsection{HPLC Analysis}

Chromatographic system: Agilent 1200 system consisting of degassing system, quaternary pump, auto loading sampler, thermostatted column compartment, diode array detector, fluorescence detector, analyte fraction collector and Agilent ChemStation software; column: Phenomenex Luna (C18) $5 \mu \mathrm{m}$ and dimensions $(250 \mathrm{~cm} \times 4.6 \mathrm{~mm})$. Chromatographic conditions: Mobile phase degassed with helium, solvent A: water containing $0.1 \%$ formic acid; solvent B: Acetonitrile containing $0.1 \%$ formic acid, Mode: flow rate, 0.8 $\mathrm{ml} / \mathrm{min}$; injection volume, $50 \mu \mathrm{l}$, detector, $\mathrm{UV}$ at 370 $\mathrm{nm}$. The eluent was monitored at several wavelengths ranging from 210 to $370 \mathrm{~nm}$, the specific wavelength of interest being $350 \mathrm{~nm}$. The HPLC operating conditions were programmed to give the following: 0 min, solvent B: $18 \% ; 15$ min, solvent B: $25 \%$; 20 min, solvent B: $35 \%, 30 \mathrm{~min}$, solvent B: $90 \%$. The run rate was $30 \mathrm{~min}$.

\subsection{Statistical Analysis}

The results of the anti-inflammatory and sedative effects of $W$. somnifera were analysed using one-way analysis of variance (ANOVA) followed by Dunnett's multiple comparison test (GraphPad Prism, version 5.0, Graph Pad software, Inc., San Diego Cap 2130, USA). Results obtained were expressed as mean ( \pm S.E.M). P-values less than 5\% $(P<0.05)$ were considered statistically significant.

\subsection{Ethical Consideration}

The experimental protocol used in this study was approved (07/04/31) by the University of the Western Cape Ethics Committee, Bellville 7535, South Africa and conforms to the University's Regulations Act concerning animal experiments.

\section{Results}

\subsection{Phytochemical Analysis}

The phytochemical qualitative analysis of the dried powdered leaf of $W$. somnifera showed the presence of triterpene steroids, saponins and tannins. 


\subsection{Pharmacological Activity Assessments, Sedative} Effect

3.2.1 Effect of Leaf Aqueous Extract of $W$. somnifera on Pentobarbitone-Induced Sleep

Pentobarbitone (40 mg/kg, i.p.) elicited sleep in 100\% of mice pretreated with physiological saline $(0.25 \mathrm{ml}$, i.p.) within $16.88 \pm 2.64 \mathrm{~min}$. Diazepam $(0.5 \mathrm{mg} / \mathrm{kg}$, i.p.) significantly prolonged the sleep produced by pentobarbitone (40 mg/kg, i.p.). The animals slept about three times longer than those given pentobarbitone $(40 \mathrm{mg} / \mathrm{kg}$, i.p.) alone. Leaf aqueous extract of $W$. somnifera $(50-200 \mathrm{mg} / \mathrm{kg}$, i.p.) dose dependently prolonged the sleep produced by pentobarbitone (40 $\mathrm{mg} / \mathrm{kg}$, i.p.). Like diazepam, $100-200 \mathrm{mg} / \mathrm{kg}$ (i.p.) of the leaf aqueous extract of the plant species significantly prolonged pentobarbitone (40 mg/kg, i.p.)-induced sleep in mice. The animals slept about four to six times longer than those given pentobarbitone (40 mg/kg, i.p.) alone. W. somnifera (50 mg/kg, i.p.) did not significantly affect pentobarbitone (40 mg/kg, i.p.)-induced sleep in mice (Table 1).
3.2.2 Effect of Leaf Aqueous Extract of $W$. somnifera on Locomotor Activity

Locomotor activity readings were obtained before and after treatment with plant extract or standard drug. Leaf aqueous extract of $W$. somnifera (50 mg/ $\mathrm{kg}$, i.p.) had little or no effect on locomotor activity. At doses of 100 and $200 \mathrm{mg} / \mathrm{kg}$ (i.p.), leaf aqueous extract of the plant species significantly and dose dependently decreased the locomotor activity by $57.26 \%$ and $59.94 \%$ respectively. Similarly, diazepam (0.5 mg/kg, i.p.) significantly decreased locomotor activity by $62.53 \%$ (Table 2).

\subsection{Anti-inflammatory Activity}

3.3.1 Effect of $W$. somnifera on Carrageenan-Induced Oedema

Carrageenan (1\%) injected into the subplantar of the right hand paws of the rats pretreated with physiological saline induced acute inflammation or oedema in the paws within $30 \mathrm{~min}$ and peaked at 90-120 min. Leaf aqueous extract of W. somnifera (25 $\mathrm{mg} / \mathrm{kg}$, i.p.) had no effect on carrageenan (1\%)-induced oedema over the $4 \mathrm{~h}$ period of testing. At doses of 50 ,

Table 1 Effect of leaf aqueous extract of $W$. somnifera on pentobarbitone-induced sleep in mice.

\begin{tabular}{lllll}
\hline $\begin{array}{l}\text { Dose }(\mathrm{mg} / \mathrm{kg}) \\
\text { Pentobarbitone }\end{array}$ & W. somnifera & Diazepam & PS (ml) & $\begin{array}{l}\text { Duration of sleep (min) } \\
\text { Mean } \pm \text { SEM }\end{array}$ \\
\hline 40 & - & - & 0.25 & $16.88 \pm 2.64$ \\
40 & - & 0.5 & - & $50.00^{*} \pm 6.36$ \\
40 & 50 & - & - & $24.00 \pm 4.15$ \\
40 & 100 & - & - & $63.13^{*} \pm 8.76$ \\
40 & 200 & - & - & $97.00^{*} \pm 15.61$ \\
\hline
\end{tabular}

${ }^{*} P<0.001$ compared to pentobarbitone $(40 \mathrm{mg} / \mathrm{kg}$, i.p.) control, ANOVA $(\mathrm{n}=8)$.

PS: Physiological saline.

Table 2 Effect of leaf aqueous extract of $W$. somnifera on locomotor activity in mice.

\begin{tabular}{lllll}
\hline \multirow{2}{*}{ Treatment group } & \multirow{2}{*}{ Dose $(\mathrm{mg} / \mathrm{kg})$} & \multicolumn{2}{c}{ Number of locomotor activity } & $\begin{array}{l}\text { Percentage decrease in } \\
\text { activity }(\%)\end{array}$ \\
\cline { 3 - 4 } & & Before treatment Mean \pm SEM & After treatment Mean \pm SEM & \\
PS & $0.25 \mathrm{ml}$ & $204.10 \pm 15.32$ & $206.80 \pm 21.93$ & 4.79 \\
W. somnifera & 50 & $215.20 \pm 25.80$ & $204.90 \pm 30.20$ & 57.26 \\
& 100 & $209.00 \pm 11.16$ & $89.32^{*} \pm 16.46$ & 59.94 \\
Diazepam & 0.5 & $214.93 \pm 10.35$ & $86.11^{*} \pm 19.67$ & 62.53 \\
\hline
\end{tabular}

${ }^{*} P<0.001$ compared to physiological saline $(0.25 \mathrm{ml})+$ control, AOVA $(\mathrm{n}=8)$.

PS: Physiological saline. Locomotor activity was counted for $15 \mathrm{~min}$. 
Table 3 Effect of $W$. somnifera on carrageenan-induced oedema in the right hind paw of rat.

\begin{tabular}{|c|c|c|c|c|c|c|c|c|c|c|}
\hline \multirow{2}{*}{$\begin{array}{l}\text { Treatment } \\
\text { group` }\end{array}$} & \multirow{2}{*}{$\begin{array}{l}\text { Dose } \\
(\mathrm{mg} / \mathrm{kg})\end{array}$} & \multicolumn{9}{|c|}{ Paw volume (ml) } \\
\hline & & $0(\min )$ & $30(\min )$ & $60(\min )$ & $90(\min )$ & $120(\min )$ & $150(\min )$ & $180(\min )$ & $210(\min )$ & $240(\mathrm{~min})$ \\
\hline UR & - & $0.61 \pm 0.08$ & $0.58 \pm 0.03$ & $0.61 \pm 0.04$ & $0.66 \pm 0.05$ & $0.57 \pm 0.02$ & $0.59 \pm 0.06$ & $0.62 \pm 0.01$ & $0.6 \pm 0.05$ & $0.58 \pm 0.03$ \\
\hline PS (ml) & 0.25 & $0.65 \pm 0.06$ & $0.88 \pm 0.06$ & $0.92 \pm 0.06$ & $0.97 \pm 0.07$ & $0.92 \pm 0.07$ & $0.65 \pm 0.09$ & $0.67 \pm 0.05$ & $0.65 \pm 0.07$ & $0.63 \pm 0.06$ \\
\hline \multirow[t]{2}{*}{$\begin{array}{l}\text { Indo-methac } \\
\text { in }\end{array}$} & 5 & $0.61 \pm 0.03$ & $0.84 \pm 0.02$ & $1.01 \pm 0.06$ & $0.99 \pm 0.03$ & $1.08 \pm 0.01$ & $0.72 \pm 0.06$ & $0.67 \pm 0.04$ & $0.68 \pm 0.04$ & $0.61 \pm 0.08$ \\
\hline & 20 & $0.55 \pm 0.04$ & $0.63 * \pm 0.02$ & $0.62 * \pm 0.05$ & $0.58^{*} \pm 0.03$ & $0.58^{*} \pm 0.02$ & $0.55 \pm 0.04$ & $0.57 \pm 0.02$ & $0.52 \pm 0.02$ & $0.53 \pm 0.03$ \\
\hline \multirow{4}{*}{$\begin{array}{l}\text { W. } \\
\text { somnifera }\end{array}$} & 25 & $0.63 \pm 0.05$ & $0.90 \pm 0.03$ & $0.87 \pm 0.01$ & $1.01 \pm 0.08$ & $0.94 \pm 0.06$ & $0.65 \pm 0.02$ & $0.66 \pm 0.05$ & $0.62 \pm 0.04$ & $0.65 \pm 0.02$ \\
\hline & 50 & $0.57 \pm 0.03$ & $0.62 * \pm 0.04$ & $0.62 * \pm 0.04$ & $0.68^{*} \pm 0.07$ & $0.73 \pm 0.06$ & $0.80 \pm 0.04$ & $0.68 \pm 0.09$ & $0.77 \pm 0.09$ & $0.72 \pm 0.07$ \\
\hline & 100 & $0.53 \pm 0.03$ & $0.70 * \pm 0.04$ & $0.60 * \pm 0.04$ & $0.70 * \pm 0.04$ & $0.72 \pm 0.07$ & $0.60 \pm 0.06$ & $0.53 \pm 0.04$ & $0.78 \pm 0.07$ & $0.68 \pm 0.05$ \\
\hline & 200 & $0.40 \pm 0.02$ & $0.60 * \pm 0.04$ & $0.58 * \pm 0.03$ & $0.77^{*} \pm 0.03$ & $0.77 \pm 0.06$ & $0.63 \pm 0.07$ & $0.58 \pm 0.03$ & $0.76 \pm 0.03$ & $0.77 \pm 0.06$ \\
\hline $\begin{array}{l}\text { Indo-methac } \\
\text { in }+W \text {. } \\
\text { somnifera } \\
\end{array}$ & $5+25$ & $0.60 \pm 0.05$ & $0.64 * \pm 0.02$ & $0.61 * \pm 0.04$ & $0.66^{*} \pm 0.01$ & $0.61 * \pm 0.04$ & $0.68 \pm 0.04$ & $0.59 \pm 0.05$ & $0.66 \pm 0.03$ & $0.64 \pm 0.02$ \\
\hline
\end{tabular}

100 and $200 \mathrm{mg} / \mathrm{kg}$ (i.p.), the plant extract significantly reduced oedema produced by carrageenan (1\%) over $90 \mathrm{~min}$ period of testing. Indomethacin $(20 \mathrm{mg} / \mathrm{kg}$, i.p. $)$ significantly reduced carrageenan (1\%)-induced oedema over $120 \mathrm{~min}$ of testing while the dose of 5 $\mathrm{mg} / \mathrm{kg}$ (i.p.) did not affect the oedema over the $4 \mathrm{hr}$ testing period. Combined administration of the lowest and sub-effective doses of leaf aqueous extract of $W$. somnifera (25 mg/kg, i.p.) and indomethacin $(5 \mathrm{mg} / \mathrm{kg}$, i.p.) produced a significant reduction in carrageenan (1\%)-induced oedema over $120 \mathrm{~min}$ of testing period (Table 3).

\subsection{Acute Toxicity Test}

There were no deaths or signs of acute toxicity observed after oral administration of 100-4,000 mg/kg of the leaf aqueous extract of Withania somnifera with the highest dose $(4,000 \mathrm{mg} / \mathrm{kg}$, p.o.) tested being the NOAEL (no-adverse-effect-level), suggesting that the $\mathrm{LD}_{50}$ was probably greater than $4,000 \mathrm{mg} / \mathrm{kg}$ (p.o.) in mice. On the other, leaf aqueous extract of the plant species at the dose range of $100-4,000 \mathrm{mg} / \mathrm{kg}$ injected into mice intraperitoneally, produced some acute toxicity symptoms such as hypolocomotor activity, piloerection, salivation and respiratory distress from the dose of $1,200 \mathrm{mg} / \mathrm{kg}$ (i.p.). Death was also observed at this dose where one mouse died. All the animals died from the dose of 2,000 $\mathrm{mg} / \mathrm{kg}$ (i.p.). The no adverse effect level (NOAEL) for the intraperitoneal injection was $800 \quad \mathrm{mg} / \mathrm{kg}$ while the lowest-observed-adverse-effect level (LOAEL) was $1,200 \mathrm{mg} / \mathrm{kg}$. The $\mathrm{LD}_{50}$ value of the leaf aqueous extract of the plant species after the intraperitoneal injection was calculated to be $1,600 \mathrm{mg} / \mathrm{kg}$.

\subsection{HPLC Analysis}

The HPLC fingerprint of the leaf aqueous extract of $W$. somnifera showed distinct peaks at the following retention times, 2.977, 3.594, 4.154, 4.406, 4.660 and 15.267 min (Fig. 1).

\section{Discussion}

In the present study, indomethacin antagonised the oedema or acute inflammation produced by carrageenan in the right hind paw of rats over $120 \mathrm{~min}$ of the $4 \mathrm{~h}$ observation period. Similarly, leaf aqueous extract of $W$. somnifera attenuated carrageenan-induced oedema but over $90 \mathrm{~min}$ of the $4 \mathrm{~h}$ observation period. Combined administration of both sub-effective doses of plant extract and indomethacin antagonised the oedema or acute inflammation produced by carrageenan in the right hind paw of rats over $120 \mathrm{~min}$ of the $4 \mathrm{~h}$ observation period. Vinegar et al. [17] reported that chemical mediators such as serotonin, 


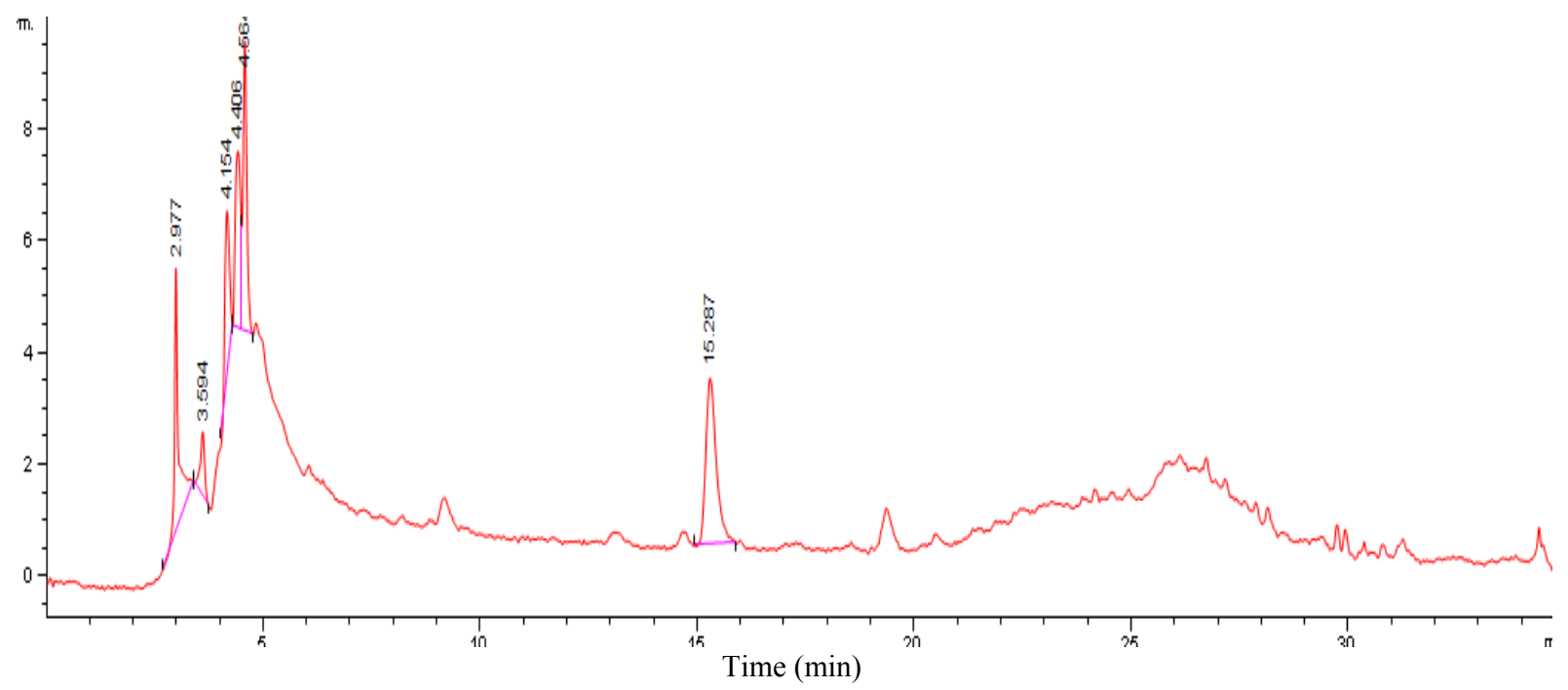

Fig. 1 HPLC fingerprint of aqueous extract of Withania somnifera.

bradykinin, histamine and prostaglandin-like substance are involved in carrageenan-induced oedema. Other reports by Adedapo et al. [18], Perianayagam et al. [19] and Swingle [20] also implicated histamine, 5-hydroxytryptamine, bradykinin and prostaglandin at different phases of carrageenan-induced rat paw oedema. Rao et al. [21] have shown that carrageenan-induced rat paw oedema test is sensitive to cyclooxygenase inhibitors and may be used to evaluate the NSAIDs (non-steroidal anti-inflammatory drugs). Indomethacin, a NSAID, is known to produce its anti-inflammatory effect by blocking cyclooxygenase activity resulting in inhibition of prostaglandin synthesis [10]. Collier et al. [22] reported that the NSAIDs may antagonise mediators such as serotonin, bradykinin and capsaicin some of which have found to be involved in carrageenan-induced rat paw oedema. It is not a coincidence; therefore, that indomethacin antagonised carrageenan-induced rat right hind paw oedema in this study. Considering the similar result obtained with both the leaf aqueous extract of the plant species and the combined treatment with both sub-effective doses of plant extract and indomethacin, it is probable that inhibition of mediators of inflammation may underpin the anti-inflammatory effect of $W$. somnifera. Pentobarbitone (a barbiturate)-induced sleep has been widely used to evaluate sedative effect of drugs [13,
15]. It has been shown that activation of $\mathrm{GABA}_{A}$ receptors mediates sleep [23]. Sedative and hypnotic effects of barbiturates have been attributed to the involvement of GABAergic mechanism [23]. In the present study, diazepam significantly prolonged sleep induced by pentobarbitone. Diazepam, a benzodiazepine, acts by enhancing GABA neurotransmission [10] and also known to promote sleep by the same mechanism [23]. It is, therefore, not surprising that diazepam prolonged pentobarbitoneinduced sleep. Similarly, leaf aqueous extract of $W$. somnifera significantly prolonged pentobarbitone-induced sleep. It is probable, therefore, that GABAergic mechanism may be involved in the sedative effect of the leaf aqueous extract of the plant species. Locomotor activity is considered as an index of alertness and its decrease is said to be an indication of sedation [24]. Maj et al. [25] showed that stimulation of central dopamine receptors caused increase in motility. Austin and Kalivas [26] have shown that central dopaminergic mechanism is involved in locomotor activity and that an increase in dopamine neurotransmission would increase locomotor activity. Enhancement of GABAergic neurotransmission has been shown to decrease central dopaminergic neurotransmission [26-28]. Mogenson and Jones [29] have reported that picrotoxin-induced locomotor 
activity was antagonised by GABA injected into the globus pallidus emanating from the ventral tegmental area of the brain. In the present study, diazepam significantly decreased locomotor activity in mice. Diazepam, a benzodiazepine [10], known to act by enhancement of GABaergic neurotransmission may be modulating central dopaminergic neurotransmission resulting in the observed decrease in locomotor activity. Leaf aqueous extract of the plant species, like diazepam, significantly decreased locomotor activity. It is tempting therefore, to suggest that the plant extract may be modulating central dopaminergic neurotransmission via GABA mechanism. The results of the phytochemical quantitative analysis done in this study showed that the plant species contains triterpene steroids, saponins and tannins. Bruneton [30] reported that saponins have both analgesic and anti-inflammatory properties. Pendota et al. [31], in their study on the anti-inflammatory, analgesic and antipyretic activities of $H$. pauciflorus showed the presence of tannins, flavonoids, steroids and/or terpenes and suggested that these activities may be due to these chemical components in the plant species. Since $W$. somnifera contains secondary metabolites such as triterpene steroids, saponins and tannins, it is possible that these metabolites may be contributing to the anti-inflammatory activity of the plant species. Even though the secondary metabolites contained in $W$. somnifera have also been mentioned in various studies as being present in many plant species which have sedative effects, none has shown any direct link between the secondary metabolites and sedation. The HPLC fingerprint of the plant species obtained revealed major characteristic peaks at the following retention times, 2.977, 3.594, 4.154, 4.406, 4.660 and $15.267 \mathrm{~min}$. The acute toxicity test carried out showed that the $\mathrm{LD}_{50}$ value obtained for $W$. somnifera could be greater than $4,000 \mathrm{mg} / \mathrm{kg}$ (p.o.). The $\mathrm{LD}_{50}$ value of the leaf aqueous extract of the plant species after the intraperitoneal injection was $1,600 \mathrm{mg} / \mathrm{kg}$.

\section{Conclusion}

The results obtained show that $W$. somnifera has both anti-inflammatory and sedative activities. The anti-inflammatory activity may be produced by the plant species inhibiting various chemical mediators including prostaglandins and bradykinin. GABaergic mechanism may underpin the sedative effect of $W$. somnifera. The $\mathrm{LD}_{50}$ values of $4,000 \mathrm{mg} / \mathrm{kg}$ (p.o.) and $1,600 \mathrm{mg}$ (i.p.) obtained for the plant species are relatively high and show that it may be safe in or nontoxic to mice. The result obtained justifies the use of the plant species by traditional medicine practitioners in South Africa for the treatment of inflammatory conditions and insomnia. However, more studies are needed to further elucidate the mechanism of the anti-inflammatory and sedative effects of $W$. somnifera.

\section{Acknowledgements}

The authors are grateful to the National Research Foundation (67983), South Africa for sponsoring the project financially. We wish to thank Kirstenbosch National Botanical Gardens, South Africa, for donating the plant species. We also wish to thank the technical staff of the Discipline of Pharmacology, University of the Western Cape, South Africa for their valuable technical assistance.

\section{References}

[1] Van Wyk, B. E., Van Oudtshoorn, B., and Gericke, N. 1997. Medicinal Plants of South Africa. Pretoria: Briza, 274-5.

[2] Watt, J. M., and Breyer-Brandwijk, M. J., (2nd ed). 1962. The Medicinal and Poisonous Plants of Southern and Eastern Africa. London: E and S Livingstone Limited, 828-9.

[3] Germisshuizen, G., and Meyer, N. L. 2003. "Plants of Southern Africa: An Annotated Checklist." Strelitzia 14: 918.

[4] Hutchings, A., and Van Staden, J. 1994. "Plants Used for Stress-Related Ailments in Traditional Zulu, Xhosa and Sotho Medicine. Part 1: Plants Used for Headache." Journal of Ethnopharmacology 43: 89-124.

[5] Watt, J. M. 1967. "African Plants Potentially Useful in 

Withania somnifera (L.) Dunal (Solanaceae) in Rats and Mice

Mental Health." Lloydia 30: 1-2.

[6] Harbone, J. B., 1984. Phytochemical Method. A Guide to Modern Techniques of Plant Analysis. 2nd ed. London: Chapman and Hall, 84-274.

[7] Ikhiri, K., Boureima, D., and Dan-kouloudo, D. 1992. "Chemical Screening of Medicinal Plants Used in the Traditional Pharmacopoeia of Niger." International Journal of Pharmacognosy 30 (4): 251-62.

[8] Kitano, Y., Makino, M., Usui, C., Takasuna, K., Kasai, Y., Hirohashi, M., Tamura, K., Takayama, S., Kojma, H., Lizuka, H., and Yanagita, T. 1994. "General Pharmacological Profile of the New Cognition-Enhancing Agent Nefiracetam." Arzneimittel-Forschung/Drug Research 44: 199-210.

[9] Williamson, E. M., Okpako, D. T., and Evans, F. J. 1996. Pharmacological Methods in Phytotherapy Research, Volume 1: Selection, Preparation and Pharmacological Evaluation of Plant Material. England: Wiley.

[10] Rang, H. P., Ritter, J. M., Flower, R. J., and Henderson, G., 8th ed. 2015. RANG and DALE'S Pharmacology. Edinburgh: Elsevier Churchill Livingstone.

[11] Miya, T. S., Holck, H. G .O., Yim, G. K. W., and Spratto, G. R. 1973. Laboratory Guide in Pharmacology. Minneapolis: Burgees Publishing Company, 44-6.

[12] Wambebe, C. 1985. "Influence of Some Agents that Affect 5-HT Metabolism and Receptors and Nitrazepam-Induced Sleep in Mice." British Journal of Pharmacology 84: 185-91.

[13] Fujimori, H., and Cobb, D. 1965. "Central Nervous System Depressant Activity of MA 1337, 3-[3, 4-M-Chlorophenyl-1-piperazyl propyl]-1-2-4(IH, 3H) Quinozotinedion Hydrochloride." Journal of Pharmacology and Experimental Therapeutics 148: 151-7.

[14] Marazioti, A., Kastellakis, A., and Antoniou, K. 2005. "Somatostatin Receptors in the Ventral Pallidum/Substantia Innominate Modulate Rat Locomotor Activity." Psychopharmacology 181: 319-26.

[15] Gupta, G., Kazmi, I., Afzal, M., Rahman, M., Saleem, S., Ashraf, M. S., Khusroo, M. J., Nazeer, K., Ahmed, S., Mujeeb, M., Ahmed, Z., and Anwar, F. 2012. "Sedative, Antiepileptic and Antipsychotic Effects of Viscum album L. (Loranthaceae) in Mice and Rats." Journal of Ethnopharmacology 141: 810-6.

[16] Lorke, D. 1983. "A New Approach to Practical Acute Toxicity Testing." Archive of Toxicology 54 (4): 275-87.

[17] Vinegar, R., Schreiber, W., and Hugo, R. 1969. "Biphasic Development of Carrageenan Edema in Rats." Journal of Pharmacology and Experimental Therapeutics 166: 96-103.

[18] Adedapo, A. A., Sofidiya, M. O., Masika, P. J., and
Afolayan, A. J. 2008. "Anti-inflammatory and Analgesic Activities of the Aqueous Extract of Acacia karoo Stem Bark in Experimental Animals." Basic and Clinical Pharmacology and Toxicology 103 (5): 397-400.

[19] Perianayagam, J. B., Sharma, S. K., and Pillai, K. K. 2006. "Anti-inflammatory Activity of Trichodesma indicum Root Extract in Experimental Animals." Journal of Ethnopharmacology 104 (3): 410-4.

[20] Swingle, K. F. 1974. "Evaluation for Anti-inflammatory Activity.” In Anti-inflammatory Agents: Chemistry and Pharmacology, edited by Scherrer R. A., and Whitehouse M. W. New York: Academic Press, 33-122.

[21] Rao, C. V., Kartik, R., Ojha, S. K., Amresh, G., and Rao, G. M. M. 2005. "Anti-inflammatory and Antinociceptive Activity of Stem Juice Powder of Tinospora cordifolia Miers. in Experimental Animals." Hamdard Medicus XLVIII: 102-6.

[22] Collier, H. O., Dinneen, L. C., Johnson, C. A., and Schneider, C. 1968. "The Abdominal Constriction Response and Its Suppression by Analgesic Drugs in the Mouse." British Journal of Pharmacology 32 (2): 295-310.

[23] Gottesmann, C. 2002. "GABA Mechanisms and Sleep." Neuroscience 111 (2): 231-9.

[24] Mahendran, G., Thamotharan, G., Sengottuvelu, S., and Narmatha-Bai, V. 2014. "Evaluation of Anticonvulsant, Sedative, Anxiolytic and Phytochemical Profile of the Methanol Extract from the Aerial Parts of Swertia corymbosa (Griseb.) Wight ex C. B. Clarke.” BioMed. Research International 2014: 1-9.

[25] Maj, J., Grabowska, M., and Gajda, L. 1972. "Effect of Apomorphine on Motility in Rats." European Journal of Pharmacology 17: 208-14.

[26] Austin, M. C., and Kalivas, P. W. 1991. "Dopaminergic Involvement in Locomotion Elicited from the VP/Substantia Innominate." Brain Research 542: 123-31.

[27] Erhard, S., Mathe, J. M., Chergui, K., Engberg, G., and Svensson, T. H. 2002. "GABA(B) Receptor-Mediated Modulation of the Firing Pattern of Ventral Tegmental Area Dopamine Neurons in Vivo." Naunyn-Schmiedebergs Archives of Pharmacology 365: 173-80.

[28] Johnson, K., Churchill, L., Klitenick, M. A., Hooks, M. S., and Kalivas, P. W. 1996. "Involvement of the Ventral Tegmental Area in Locomotion Elicited from NAc or Ventral Pallidum." Journal of Pharmacology and Experimental Therapeutics 277: 1122-31.

[29] Mogenson, G. J., Wu, M., and Jones, D. L. 1980. "Lomotor Activity Elicited by Injections of Picrotoxin into the Ventral Tegmental Area Is Attenuated by Injections of GABA into the Globus Pallidus." Brain Research 191: 569-71. 

Withania somnifera (L.) Dunal (Solanaceae) in Rats and Mice

[30] Bruneton, J. 1998. Pharmacognosy, Phytochemistry, Medicinal Plants. Hampsphire: Intercept.

[31] Pendota, S. C., Yakubu, M. T., Grierson, D. S., and Afolayan, A. J. 2009. "Anti-inflammatory, Analgesic and
Antipyretic Activities of the Aqueous Extract of Hippobromus pauciflorus (L.f.) Radlk Leaves in Male Wistar Rats." African Journal of Biotechnology 8 (10): 2036-41. 